\title{
A Rapid and Simple Genotyping Method for Various Plants by Direct-PCR
}

\author{
Hyunsik Hwang ${ }^{1}$, Shin-Chul Bae ${ }^{1}$, Seungbum Lee ${ }^{1}$, Yeon-Hee Lee ${ }^{1}$, Ancheol Chang ${ }^{1}$ * \\ ${ }^{1}$ Department of Agricultural Biotechnology, National Academy of Agricultural Science, Rural Development Administration, Suwon, \\ 441-707, Korea
}

\begin{abstract}
Conventional PCR requires purified DNA molecules as templates. Purification of DNA molecules from a large number of samples is laborious, costly and time-consuming. Therefore, various direct-PCR methods using tissues directly employed as templates have been developed. Using direct-PCR, one can deal with large number of plant samples far more rapidly and efficiently. However, conditions and methods of direct-PCR vary for different plant samples. This is why applications of direct-PCR technology to plant science have been limited. In this study, we have established the appropriate condition for effectively lysing various plant cells and developed the plant cell lysis buffer named 'Alkaline PEG lysis buffer' for the direct-PCR. The direct-PCR technology using a newly developed Alkaline PEG lysis buffer successfully amplified different targeted endogenous genes in seven different plant species. This technology is expected to be very useful and effective tool in plant breeding dealing with large number of plants for the selection of targeted traits, markers and pedigrees.
\end{abstract}

Keywords Alkaline lysis buffer, Direct-PCR, Genotyping, Transgenes

\section{INTRODUCTION}

Polymerase chain reaction (PCR) is a technology which simply amplifies the nucleic acid, and very useful and strong gene analysis techniques widely used in various biological researches and diagnosis (Florencia et al. 2006). Particularly, in the field of plant research, PCR has been widely applied to almost all research fields of plant molecular biology, thremmatology and ecology including gene type analyses, drawing gene maps, gene isolation, as well as verification of gene insertion into transformants and developing markers.

Traditional PCR technology requires isolation and purification of the template DNA. This process consists of two steps. The first step is to crush the tissues and cells to easily elute the DNA inside the plant cells. Physical methods including grinding plant tissues after freezing them with the liquid nitrogen, and chemical methods including lysing the plant cells with the protein lysis enzymes (proteinase K) and the detergent are mainly used. The second step is to eliminate chemical substances including enzymes which may degrade DNA molecules or interfere with the PCR reaction from various eluted cellular components after lysing the plant cells or secondary metabolites and to purify the DNA only (Yang et al. 2007). These separation and purification processes of the template DNA require a lot of labors, time and cost because the processes show complicated conditions depending on various plant types and tissues, and when the processes deal with a lot of samples.

Since 1990s various methods have been developed to easily and quickly extract the plant DNA for the PCR. The genomic DNA inside the plant cell may be easily isolated from the secondary metabolites including phenolic compounds which combine with the DNA inside the cell even after lysing cells and other materials by using various plant cell lysis buffers such as Alkaline buffer (Wang et al. 1993; Xin et al. 2003), the PVPP (Polyvinylpyrrolidone) (John 1992; Kim et al. 1997), the ROSE buffer (Steiner et al. 1995) and

Received July 16, 2013; Revised August 21, 2013; Accepted August 27, 2013; Published September 30, 2013

*Corresponding author Ancheol Chang, abychan@korea.kr, Tel: +82-31-299-1751, Fax: +82-31-299-1722 
the CTAB (Cetyltrimethyammonium bromide) (Hwang et al. 2000). Meanwhile, the Direct-PCR technology which directly used animal, microbial or plant tissues to the PCR without the DNA isolation and purification processes was developed (Pierre and Christian 1991; Victor et al. 1993; Yang et al. 2007; Dirk et al. 2010). Such makes direct-PCR technology an efficient, faster and convenient method while at the same time it saves cost and is time-efficient over the traditional PCR. However, sometimes it may be difficult to achieve accurate results in the field of plant science because various elements such as secondary metabolites, enzymes and phenolic compounds in plant cells may impede PCR reactions.

Several commercial products (HelixAmp direct PCR (3G), Nanohelix Co. Korea and Phire Direct PCR kit, Thermo Fisher Scientific Co., USA) have been developed and provided for the Direct-PCR. However, their applications have been limited to mainly animals and microbes, and caused some problems if applied to various plants. Recently, the technical demand for the Direct-PCR has surged in the plant science to develop GMO crops or perform gene function verification studies on various plants but the technical development lags behind this trend. Therefore, in this study we have developed a new plant cell lysis buffer by modifying the existing cell lysis buffers (alkaline polyethylene glycol, Piotr and Michal 2006), to expand the application scope of Direct-PCR technology to more various plants. The DirectPCR technology using newly developed plant cell lysis buffer (Alkaline PEG lysis buffer) is expected to be applied to genotyping of various plants; to save time, efforts and cost especially for marker-assisted selection of pedigrees in traditional plant breeding and development of genetically modified crops.

\section{MATERIALS AND METHODS}

\section{Plant materials}

To establish the optimal $\mathrm{NaOH}$ concentration to plant cell lysis for Direct-PCR, three plant species were used: the leaf tissues of rice ( $c v$. Dongjin) grown for 70 days in a greenhouse after seeding on the topsoil, the leaf tissues of arabidopsis ( $c v$. Columbia-0) grown in a growth chamber for 30 days after seeding on topsoil, and the leaf tissues of potato ( $c v$. Superior) grown for 30 days after transplanting on the topsoil in a growth chamber.

In addition to the aforementioned plant species, four more were used in genotyping analyses of endogenous genes by direct-PCR which include tobacco, tomato, chrysanthemum and rape. Tobacco ( $c v$. Xanthi), tomato ( $c v$. Microtome) and rape ( $c v$. Yeongsan) were grown for 30 days, while chrysanthemum ( $c v$. Shinma) was grown for 40 days in a greenhouse. Leaf tissues of all plants were used in all experiments.

To confirm the presence of transgenes by direct-PCR, a total of six plant species were used. All transgenic plants were grown in a greenhouse after Agrobacterium-mediated transformation and plant regeneration. Leaf tissues of three independent lines for each transgenic plant species were used in this experiment. Plant materials and target genes investigated in this study are listed in Table 1.

\section{Preparation of plant cell lysis buffer}

The plant cell lysis buffers were prepared by adding seven different concentrations of $\mathrm{NaOH}(0,1,5,10,20,50$, $100 \mathrm{mM}$ ) to 6\% PEG 200 (Sigma-Aldrich Co., USA) solution. The plant cell lysis buffer named "Alkaline PEG lysis buffer" was freshly prepared right before every use.

\section{Plant cell lysis and direct-PCR amplification}

Plant leaf tissues were cut by a $1.0 \mathrm{~mm}$ in $\mathrm{dm}$ puncher made by Harris Uni-core (Ted Pella Inc., USA) and each sample was soaked into a PCR tube containing $50 \mathrm{ul}$ of freshly prepared Alkaline PEG lysis buffer. After a brief vortexing, solution on the wall of tube was collected by brief spin down and tubes were kept on ice until all samples were prepared. The tubes were incubated at room temperature for $1 \mathrm{~min}$ for cell lysis. Then, the samples were kept on ice until used for direct-PCR or stored at $-20^{\circ} \mathrm{C}$ for future use. A total of $2 \mathrm{ul}$ of each plant lysate was added to a PCR tube containing 48 ul of AccuPower PCR premix (Bioneer Co., Korea). The PCR reaction was performed in a total volume of $20 \mathrm{ul}$. The PCR conditions were consisted of initial denaturation at $95^{\circ} \mathrm{C}$ for $5 \mathrm{~min}$, followed by 35 cycles of 9 $5^{\circ} \mathrm{C}$ for $30 \mathrm{sec}, 60^{\circ} \mathrm{C}$ for $30 \mathrm{sec}$, and $72^{\circ} \mathrm{C}$ for $30 \mathrm{sec}$, and a final extension step at $72^{\circ} \mathrm{C}$ for $5 \mathrm{~min}$. Products of plant 


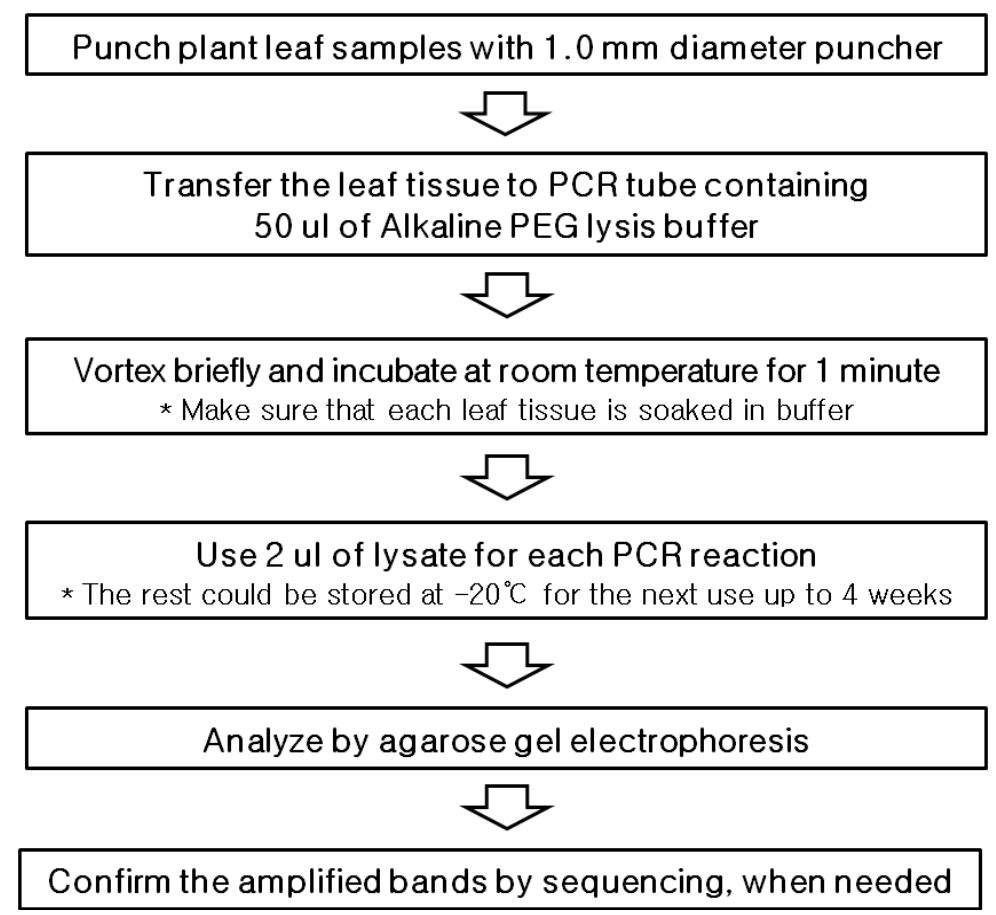

Fig. 1. Working flow chart of direct-PCR for plant genotyping. The newly optimized 'Alkaline PEG lysis buffer' was prepared by mixing PEG and $\mathrm{NaOH}$. Each plant leaf tissue punched with $1.0 \mathrm{~mm}$ diameter puncher was soaked in $50 \mu \mathrm{l}$ of the buffer. Vortex briefly and incubate at room temperature for one minute. About $2 \mathrm{ul}$ of lysate of each sample was used for PCR reaction. Various genes were successfully amplified from various plant leaf samples.

direct-PCR were analyzed on $1.5 \%$ agarose gel electrophoresis. A PCR product of each plant was randomly selected and sequenced, and each of targeted genes was confirmed by blasting at http://blast.ncbi.nlm.nih.gov/ Blast.cgi. Procedures of plant direct-PCR using Alkaline PEG lysis buffer are presented in Fig. 1. All primers used for genotyping different genes in various plants are shown in Table 1.

\section{RESULTS AND DISCUSSION}

\section{Determination of plant cell lysis buffer conditions for direct-PCR}

Recently, commercial direct-PCR kits using detergents and PCR enhancing enzymes have been provided. However, published method employing alkaline lysis for direct PCR requires additional step, including dilution of lysate or mixing other buffers prior to PCR (Chum et al. 2012; Dirk et al. 2010). A previous study on alkaline lysis buffer-based
direct-PCR showed that amplification of human genes from human cells or tissues was successful; however, it was not in the case of plant samples (Piotr and Michal 2006). This study aimed to develop a new plant cell lysis buffer for the simple and rapid plant direct-PCR method and to extend its application range to various plants. Therefore, to investigate the optimal concentration of $\mathrm{NaOH}$ in the plant cell lysis buffer, seven different types of plant cell lysis buffers containing $0,1,5,10,20,50$ and $100 \mathrm{mM}$ of $\mathrm{NaOH}$ in $6 \%$ PEG 200 solution were prepared and tested. DirectPCR analysis of leaf tissues of rice- a monocotyledonous model plant, Arabidopsis- a dicotyledonous model plant and potato having relatively large size of genomes (triploid genome) was performed under the same condition with seven different types of plant cell lysis buffers.

The results of direct-PCR for TPI genes in rice showed that the gene could be successfully amplified using all seven types of buffers. However, agarose gel electrophoresis analysis revealed that $20 \mathrm{mM}$ of $\mathrm{NaOH}$ in the lysis buffer showed the most effective amplification of the gene 
Table 1. Plant materials and primer sequences used for direct-PCR.

\begin{tabular}{|c|c|c|c|c|c|}
\hline Plant & Cultivar & $\begin{array}{c}\text { Name of } \\
\text { gene }\end{array}$ & $\begin{array}{c}\text { Size of } \\
\text { amplicon (bp) }\end{array}$ & $\begin{array}{l}\text { GI No. } \\
\text { (NCBI) }\end{array}$ & Primer sequences $\left(5^{\prime}->3^{\prime}\right)$ \\
\hline \multicolumn{6}{|l|}{ Endogenous genes } \\
\hline Rice & Dongjin & OsTPI & 360 & 115434515 & $\begin{array}{l}\text { Forward AGCTAGCCTGCCTTCACTTG } \\
\text { Reverse CGTTATCCCCAGGTTTGGCT }\end{array}$ \\
\hline Arabidopsis & Columbia- 0 & AtActin & 491 & 145361675 & $\begin{array}{l}\text { Forward GGCGATGAAGCTCAATCCAAAC } \\
\text { Reverse GGTCACGACCAGCAAGATCAAG }\end{array}$ \\
\hline Tobacco & Xanthi & NtActin & 524 & 20038 & $\begin{array}{l}\text { Forward CCСТCCCACATGCTATTCT } \\
\text { Reverse AGAGCCTCCAATCCAGACA }\end{array}$ \\
\hline Potato & Superior & StActin & 320 & 460408873 & $\begin{array}{l}\text { Forward TCCTCCATTGAAAAGAACTATG } \\
\text { Reverse CCAGACACTGTACTTTCTCTC }\end{array}$ \\
\hline Tomato & Microtome & SlActin & 247 & 460378622 & $\begin{array}{l}\text { Forward CTCGAGCAGTGTTTCCCAGT } \\
\text { Reverse GGTGCCTCAGTCAGGAGAAC }\end{array}$ \\
\hline Chrysanthemum & Shinma & CmActin & 243 & 475393035 & $\begin{array}{l}\text { Forward TGCTGACAGGATGAGCAAGG } \\
\text { Reverse GGGCCAGACTCGTCGTATTC }\end{array}$ \\
\hline Rape & Youngsan & BnActin & 512 & 4139263 & $\begin{array}{l}\text { Forward TCACCATCGGAGCTGAGAGA } \\
\text { Reverse TGGACCCGACTCATCGTACT }\end{array}$ \\
\hline \multicolumn{6}{|l|}{ Transgenes } \\
\hline Rice & Dongjin & CrylAc & 658 & 22415750 & $\begin{array}{l}\text { Forward TTGTGGCTCTCTTCCCGAAC } \\
\text { Reverse AACTCGGCAGAACGGTGAAT }\end{array}$ \\
\hline $\begin{array}{c}\text { Arabidopsis } \\
\text { Chrysanthemum }\end{array}$ & $\begin{array}{l}\text { Columbia-0 } \\
\text { Shinma }\end{array}$ & Hyg & 510 & 34596493 & $\begin{array}{l}\text { Forward CGTCTGCTGCTCCATACAAG } \\
\text { Reverse GTGCTTGACATTGGGGAGTT }\end{array}$ \\
\hline Tobacco & Xanthi & $\operatorname{Bar}(p p t)$ & 170 & 375153555 & Forward TACACCCACCTGCTGAAGTC \\
\hline Rape & Youngsan & & & & Reverse AAACCCACGTCATGCCAGTT \\
\hline Potato & Superior & $\begin{array}{c}K m \\
(N p t I I)\end{array}$ & 249 & 19569229 & $\begin{array}{l}\text { Forward CAAGATGGATTGCACGCAGG } \\
\text { Reverse TTCAGTGACAACGTCGAGCA }\end{array}$ \\
\hline
\end{tabular}

(Fig. 2).

In Arabidopsis, it was found that cell lysis buffers containing $\mathrm{NaOH}$ concentration between 5 and $20 \mathrm{mM}$ were effective in amplifying Actin genes. Results using potato samples showed that 5 to $50 \mathrm{mM}$ of $\mathrm{NaOH}$ in the lysis buffer were very effective in amplifying the targeted Actin genes. Three repetitive experiments for each plant showed the same results (data not shown). With all the results combined, 20 $\mathrm{mM}$ of $\mathrm{NaOH}$ added to the plant cell lysis buffer is the commonly effective concentration that amplified target genes in three plant species. Therefore, this lysis buffer concentration $(20 \mathrm{mM}$ of $\mathrm{NaOH}$ and $6 \%$ of PEG 200) hereto named Alkaline PEG lysis buffer was employed in all subsequent direct-PCR experiments in this study. Table
1 shows the plants, target genes and primer sequences used in the experiment.

In all studies with three different plant species, the target genes were amplified when the $\mathrm{NaOH}$ concentration of the plant cell lysis buffer ranged from 5 to $50 \mathrm{mM}$ but failed to amplify the genes when $100 \mathrm{mM}$ of $\mathrm{NaOH}$ was added. Being an organic polymer compound, the PEG component of plant lysis buffer, plays a role in neutralization after lysing plant cells and reducing inhibition, which may be caused by high $\mathrm{pH}$, in the following PCR reaction. In this study, however, it is thought that the target genes were not effectively amplified by negative effect of $100 \mathrm{mM}$ of $\mathrm{NaOH}$ in the lysis buffer. Previous direct-PCR experiments using high alkaline lysis buffer ranging from 12 to 13 of $\mathrm{pH}$ 

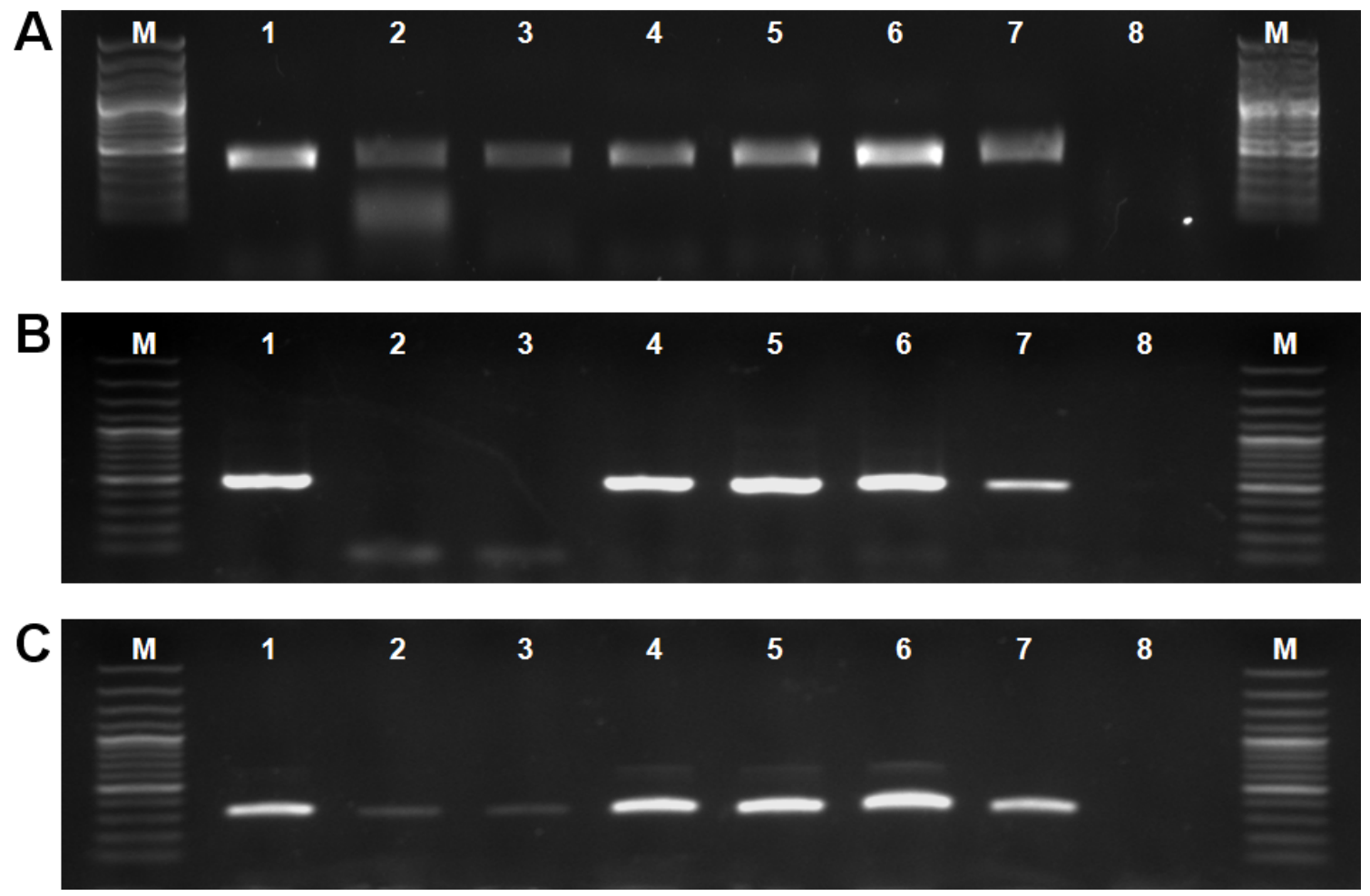

Fig. 2. Analyses of PCR products amplified from various plant leaf tissues lysed by different concentration of $\mathrm{NaOH}$. PCR products were loaded on lane 2 to $8(\mathrm{NaOH}$ concentration $0,1,5,10,20,50,100 \mathrm{mM}$ in $6 \%$ PEG200 solution, respectively) and they were compared to those amplified with a commercial direct-PCR kit on lane 1. Each plant leaf sample was lysed in $50 \mathrm{ul}$ of the lysis buffer for one minute at room temperature. A total of $2 \mathrm{ul}$ of each lysate was used for each PCR reaction in a total volume of $20 \mathrm{ul}$. A. rice, TPI (360bp), B. Arabidopsis, Actin (491bp), C. potato, Actin (320bp). No template control PCR reactions (without lysates) were performed at the same time and no PCR product could be seen from all on the gel (data not shown).

showed similar results (Piotr and Michal 2006). This indicates that $100 \mathrm{mM}$ of $\mathrm{NaOH}$ may exceed the neutralization limit of PEG in the buffer and affect negatively on the following PCR reaction.

In addition, our data showed that $20 \mathrm{mM}$ of the $\mathrm{NaOH}$ was the optimal concentration of the plant cell lysis buffer for three different plant species. This result shows large difference in $20 \mathrm{mM}$ of $\mathrm{KOH}$ concentration of the cell lysis buffer for the Direct-PCR on microbes or animal cells (Piotr and Michal 2006). Therefore, our findings suggest that relatively high $\mathrm{pH}$ is required for effective lysis of plant cells compared to microbes or animal cells; and a plantspecific cell lysis buffer is required considering characteristics and components of plant cells.

\section{Application of Direct-PCR for various plants}

Direct-PCR experiments for seven different plant species were performed to investigate whether the newly developed Alkaline PEG lysis buffer based on the results above may be applied to a wider range of plant species. Table 1 shows plants, target genes and primers used in these experiments. As mentioned earlier each of the three different endogenous target genes was amplified from the corresponding leaf tissues of rice, arabidopsis and potato by direct-PCR using Alkaline PEG lysis buffer (Fig. 3). In addition, it was found that the targeted Actin genes were effectively amplified by the direct-PCR using leaf tissues of tobacco, potato, chrysanthemum, and rape indicating that this technology may be applied to various plants with ease. We confirmed the PCR products and the target genes through sequencing analysis and blast searching at http://blast.ncbi.nlm.nih. 


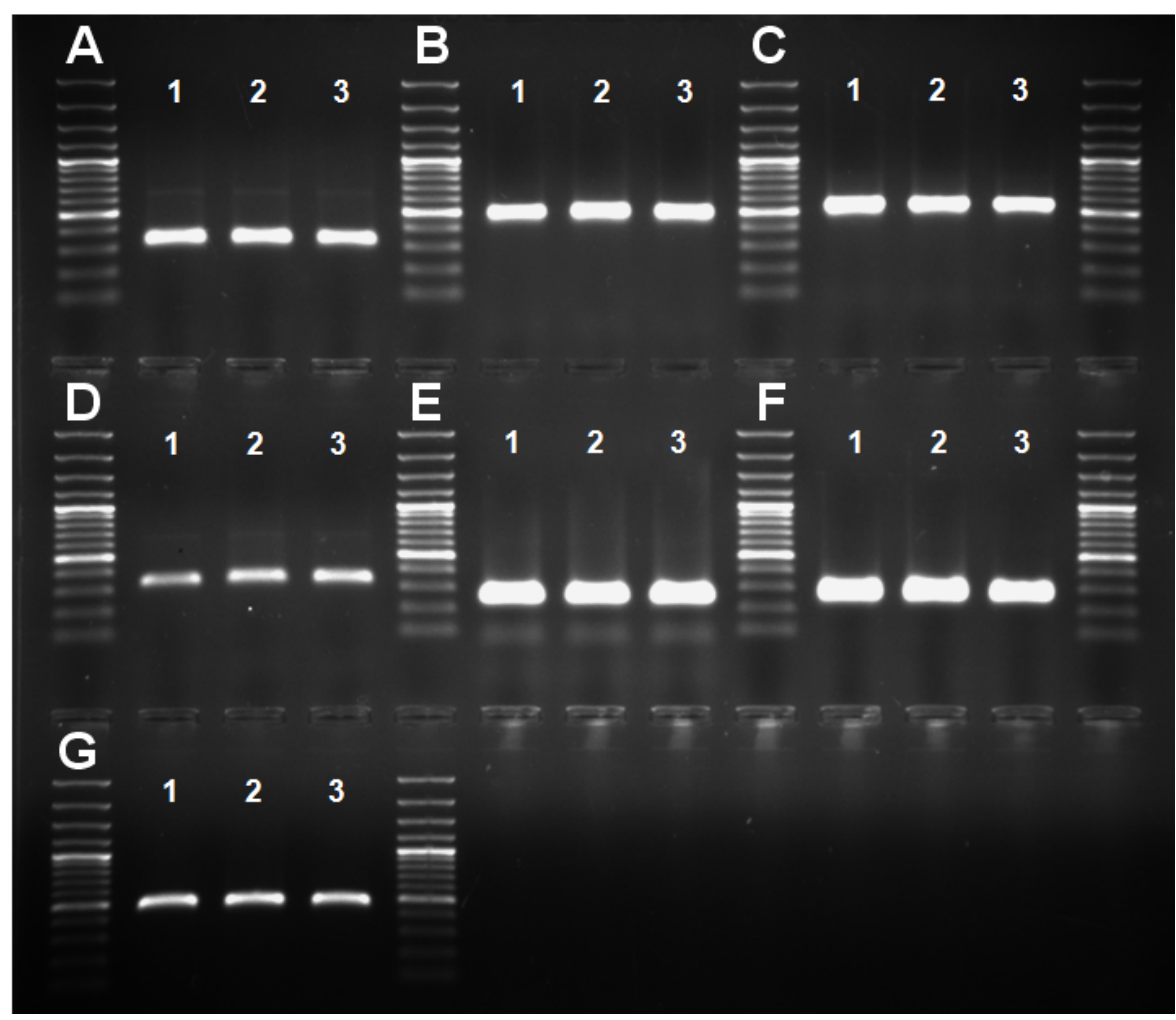

Fig. 3. Direct-PCR amplification of endogenous genes from various plants using the new 'Alkaline PEG lysis buffer'. A 35-cycle PCR was performed with selected primers for each gene of different plants. PCR product of 3 independent lines of each plant was loaded on lane 1 to 3, respectively. A. Rice TPI, 360bp B. Arabidopsis Actin, $491 \mathrm{bp}$ C. Tobacco Actin, 524bp D. Potato Actin, 320bp E. Tomato Actin, 247bp F. Chrysanthemum Actin, 243bp G. Rape Actin, 512bp. No template control PCR reactions (without lysates) were performed at the same time and no PCR product could be seen from all on the gel (data not shown). A PCR product of each plant was randomly selected and sequenced. Finally, each of targeted genes was confirmed by blasting at http://blast.ncbi.nlm.nih.gov/Blast.cgi (data not shown).

gov/Blast.cgi (data not shown). Furthermore, the directPCR technology may be applied to plants such as potato and chrysanthemum, which have large genome sizes and difficulties in the DNA purification due to relatively large amount of glucose or secondary metabolites compared to other plants. Therefore, this technology is expected to be effective and useful in marker-assisted mass selection of pedigrees in big populations.

\section{Genotyping of transgenes by direct-PCR in various transgenic plants}

The direct-PCR technology using Alkaline PEG lysis buffer was also tested to amplify transgenes in various transgenic plants. In these experiments, crylAc gene in rice, hyg, a selective marker gene in arabidopsis and chrysanthemum, bar, a selective marker gene in tobacco and rape, and $\mathrm{Km}$ (NptII), a selective marker gene in potato were successfully amplified by direct-PCR (Fig. 4). Target genes were confirmed by sequencing a randomly selected PCR product of each plant and blasting the sequences at http://blast.ncbi.nlm.nih.gov /Blast.cgi (data not shown). The results indicated that this direct-PCR technology may be applied to genotyping of transgenes in various transgenic plants and can be used as an effective tool for screening transgenic plants in molecular plant breeding.

The direct-PCR product similar in size to the selection marker gene, NPTII was observed in the control group of potato wild type plants (Fig. 4D lane 1). This PCR product was also observed in independent PCR analyses using additionally separated and purified genomic DNA (data not 


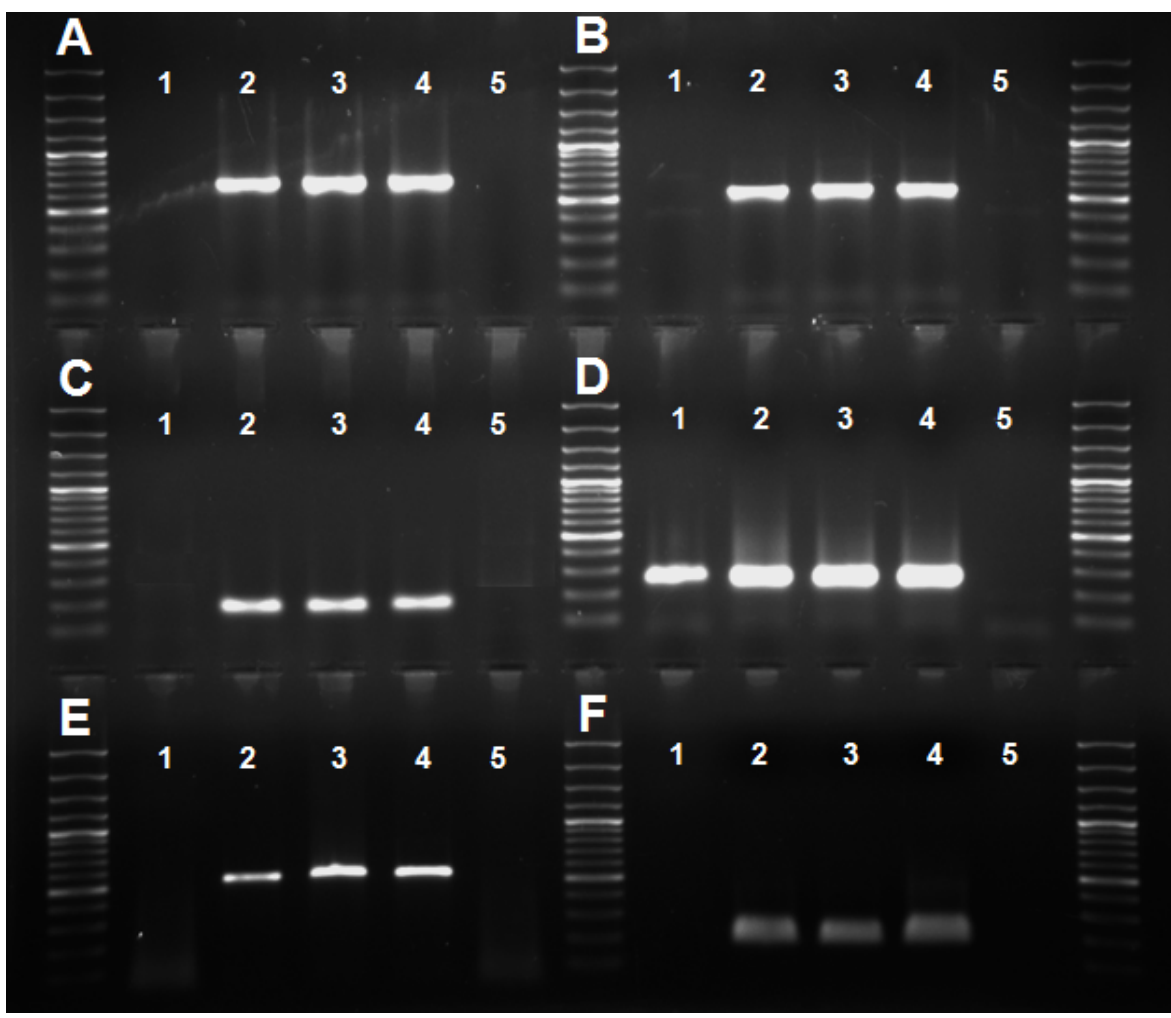

Fig. 4. Amplification of transgenes from various plant species by direct-PCR. A. Rice, CrylAc (658bp) B. Arabidopsis, Hyg (510bp), C. Tobacco, Bar (170bp), D. Potato, Km (NPTII) (249bp), E. Chrysanthemum, Hyg (510bp) F Rape, $\operatorname{Bar}(170 \mathrm{bp})$. Lane 1 is Wt; wild type and Lane 5 contains no template control PCR reaction. Lane 2 to 4 represents three independent $T_{0}$ transgenic plant lines of each plant species (A and $C$ to $F$ ) or three independent $T_{1}$ transgenic plant lines of Arabidopsis (B). A PCR product of each plant species was randomly selected and sequenced. Finally, each of target genes was verified by blasting sequences at http://blast.ncbi.nlm.nih.gov/Blast.cgi (data not shown).

shown). This PCR product requires further analyses including base sequences. Although there are possibilities that the product came from a cross-contamination of the template DNA or it may be a non-specifically amplified fragment due to a coincidence between primer sequences and a genomic DNA region rather than the targeted selection marker gene. A similar non-specific product from a PCR with NPTII gene-specific primers in tobacco plants has been reported by Jian et al. (2009). Although PEG was implicated to possibly affect amplification and specificity of PCR (Pomp and Madrano 1991), it is also worth taking precautions especially in designing primers with sequences that are unique only to the target gene, as well as not to make cross-contamination with the other template DNA.

Here, we have reported that our Alkaline PEG lysis buffer is able to expand the application range of the directPCR technology to various plant species and confirmed that this technology can be applied with various purposes. In addition, utilizing this newly optimized lysis buffer, would reduce the cost compared to using commercial direct-PCR kits. In particular, this direct-PCR technology using the Alkaline PEG lysis buffer is expected to be a strong tool which can be rapidly and simply used for genotyping and screening pedigrees of various plants at low cost and labor without DNA purification.

\section{CONCLUSION}

Our study established the appropriate condition for effectively lysing various plant cells and developed the plant cell lysis buffer named 'Alkaline PEG lysis buffer' for the direct-PCR. The direct-PCR technology using newly developed Alkaline PEG lysis buffer successfully amplified different 
targeted endogenous genes from seven different plant species. This finding is highly significant as the scope of this directPCR technology application is deemed to cover more various plant species. Furthermore, this direct-PCR technology is expected to be utilized as very effective and useful tool in both fields of traditional and molecular plant breeding dealing with large number of plants for the selection of targeted traits or markers. Future research exploring the probable application of this technology to gene expression analysis will be carried out.

\section{ACKNOWLEDGMENT}

The study is a part of the Rural Development Administration (RDA) agenda project (No: PJ0086342013) performed under the support of RDA.

The authors also express great appreciation to Dr. ShinChul Bae, Dr. Myung-Ok Byun, Dr. Seungbum Lee, Dr. Du-Ri Kim, Dr. Bum-Soo Han and Dr. Kyung-Hee Roh in National Academy of Agricultural Science of Rural Development Administration for providing plant materials for the study.

\section{REFERENCES}

Chum PY, Haimes JD, Andre CP, Kuusisto PK, Kelly ML. 2012. Genotyping of plant and animal samples without prior DNA purification. J. Vis. Exp. 67; e3844, doi: $10.3791 / 3844$.

Dirk UB, Michael DP, Christiaan JV, Margaret JV, Berit G. 2010. A rapid and inexpensive method for the direct PCR amplification of DNA from plants. American J. Botany. e65-e68.

Florencia G, Irene S, Veronica F. 2006. Fragile-X Mental Retardation; Molecular diagnosis in argentine patients. J
Biochem Mol Biol. 39: 766-773.

Hwang SK, Kim YM. 2000. A simple and reliable method for preparation of cross-contaimnination-free plant genomic DNA for PCR-based detection of transgenes. J Biochem Mol Biol. 33: 537-546.

Jian W, Qinling S, Na T, Liyu C, Ziqin X, Jianbin Z. 2009. Electrochemical detection of the neomycin phosphotransferase gene (NPT-II) in transgenic plants with a novel DNA biosensor. J Appl Electrochem. 39: 935-945.

John ME. 1992. An efficient method for isolation of RNA and DNA from plants containing polyphenolics. Nucleic acids Res. 20: 2381.

Kim CS, Lee DH, Shin JS, Chung YS, Hyung NI. 1997. A simple and rapid method for isolation DNA from fruit trees and conifers using PVP. Nucleic Acids Res. 25: 1085-1086.

Pierre B, Christian M. 1991. Direct amplification of plant genomic DNA from leaf and root pieces using PCR. Plant Mol Biol. 17: 555-557.

Piotr C, Michal R. 2006. Alkaline polyethylene glycol- based method for direct PCR from bacteria, eukaryotic tissue samples, and whole blood. Biotechniques. 40: 454-458.

Pomp D, Madrano JF. 1991. Organic solvents as facilitators of polymerase chain reaction. Biotechniques. 10: 58-59

Steiner JJ, Poklemba CJ, Fjellstrom RG, Elliott LF. 1995. A rapid one-tube genomic DNA extraction process for PCR and RAPD analyses. Nucleic acids Res. 23: 2569-2570.

Victor IK, Bernard JC, Colwyn MT, Jonathan DGJ. 1993. Alkali treatment for rapid preparation of plant material for reliable PCR analysis. The plant journal. 3: 493-494.

Wang HQM, Cuter AJ. 1993. A simple method of preparing plant samples for PCR. Nucleic acids Res. 21: 4153-4154.

Xin Z, Velten JP, Oliver MJ, Burke JJ. 2003. High throughput DNA extraction method suitable for PCR. Biotechniques. 34: 820-824, 826.

Yang GY, Kim JY, Soh MS, Kim DS. 2007. A simple and rapid gene amplification from Arabidopsis leaves using anydirect system. J Biochem Mol Biol. 40: 444-447. 